\title{
Comparative Analysis on the Fracture Resistance of Different Types of Asphalt Mixture
}

\author{
Wu Xirong \\ Key Laboratory of Highway Construction \& Maintenance Technique in Loess Region, \\ Shanxi Provincial Research Institute of Communications, Taiyuan 030006, Shanxi;
}

Key words: asphalt mixtures; anti-cracking performance; evaluation method; fracture energy; J-integral; curvature strain energy

Abstract: Bending strain density threshold based on elastic damage theory, the $\mathrm{j}$-integral based on elastic plastic fracture mechanics and Cohesion and crack opening displacement based on cohesive zone model were employed to evaluate the fracture resistance of asphalt mixture of SMA-13、 AC-13 and $\mathrm{CAM}$ in the temperature of $10^{\circ} \mathrm{C} 、 5^{\circ} \mathrm{C} 、 0^{\circ} \mathrm{C} 、-5^{\circ} \mathrm{C} 、-10^{\circ} \mathrm{C}$. The results of the study shows when the temperature is below $0^{\circ} \mathrm{C}$, bending strain density threshold which was used to evaluate crack resistance of asphalt mixture is reasonable, using fracture toughness, cohesion and crack opening displacement index to evaluate the crack resistance property of three kinds of asphalt mixture, the test results are consistent, test results are consistent, namely anti-cracking performance of SMA-13 is optimal, the second is AC-13 and CAM. In addition, the higher temperature is, the better the crack resistance of asphalt mixture.

In order to evaluate crack resistance of asphalt mixture, the researchers have done a lot of experiments and research, different test methods and evaluation indexes are put forward.

The test methods and evaluation indexes which are frequently used at home and abroad at present are mainly indirect tensile test, direct tensile test, low-temperature bending test, constraints temperature stress test specimens (frozen), the stress relaxation test, low temperature shrinkage coefficient test, a constrained beams of three point bending, $\mathrm{J}$-integral test, $\mathrm{C} *$ integral test, fatigue test, direct tensile fatigue, indirect tensile fatigue, low temperature bending creep test, direct tensile creep, the indirect tensile creep and uniaxial compression test, freeze-thaw cycling test and freeze-thaw splitting test ${ }^{[1-3]}$. But there is no accepted standard evaluation method.

In fact, based on different evaluation methods, performance of asphalt mixture at low temperature is not entirely consistent ${ }^{[4]}$. Different evaluation methods have their respective applicable scope. At present, the low temperature bending test is commonly used to evaluate the low temperature crack resistance of asphalt mixture,

However, the researches point out that this method is difficult to fully reflect the mixture of the low temperature crack resistance, evaluated result for modified asphalt mixture and Large porous asphalt mixture is incorrect ${ }^{[5]}$. Based on this reason, scholars put forward the energy evaluation inde ${ }^{[6]}$. Another method commonly used is the low temperature bending creep test, which difficult to determine the stress level of modified asphalt mixture. Hao peiwen and others think that $0{ }^{\circ} \mathrm{C}$ compressive strain can be used as evaluation index at low temperature anti-cracking performance, the method is simple easy to promote ${ }^{[7]}$.Others thinks, the critical stress intensity factor is an reasonable index of crack resistance, but this index used for evaluate crack resistance of viscoelastic material under a certain temperature is unreasonable, the $\mathbf{J}$ integral based on elastic-plastic mechanics theory more reasonable ${ }^{[8]}$. Dongre ${ }^{[9]}$ adapts bending beam test to evaluate the low 
temperature crack resistance of asphalt mixture and show that fracture toughness than the critical stress intensity factor of asphalt mixture stiffness is more sensitive and more suited to evaluate crack resistance characteristics of asphalt mixture; Zhang dong think the bilinear CZM anti-cracking performance evaluation method is reasonable and comprehensive ${ }^{[10-11]}$.

Based on the above research, the bending strain density threshold based on the theory of the elastic damage theory of fracture mechanics, $\mathbf{J}$ integral based on the elastic-plastic and cohesion and crack opening based on double linear model were selected to comprehensive evaluated the crack resistance of asphalt mixture. Based on the above evaluation index, crack resistance of different structure types of asphalt mixture compared and analyzed.

\section{The evaluation index}

\section{Bending strain energy density threshold}

Under the condition of low temperature, asphalt concrete can be regarded as elastic material .Cracking destruction process under external load is a process of energy dissipation. Above all, the work done by outside force as the elastic strain energy is stored. When fracture occurrence, development, produce new surface, the energy turned into surface energy. General speaking, the stronger the ability of stored the elastic strain energy, the better the crack resistance ${ }^{[12] .}$

Assume that material damage forms correspond to state of energy per unit volume, then, the material damage can be expressed using strain energy density function.

$$
\frac{d W}{d V}=\int_{0}^{\varepsilon_{0}} \sigma_{i j} d \varepsilon_{i j}
$$

$\frac{d W}{d V}$ is strain energy density function; $\sigma_{i j}, \varepsilon_{i j}$ are Stress and strain component; $\varepsilon_{0}$ is the maximum strain which correspond to the maximum stress; Threshold of $\frac{d W}{d V}$ is the area of the actual under uniaxial stress strain relation curve (as shown in fig1)。

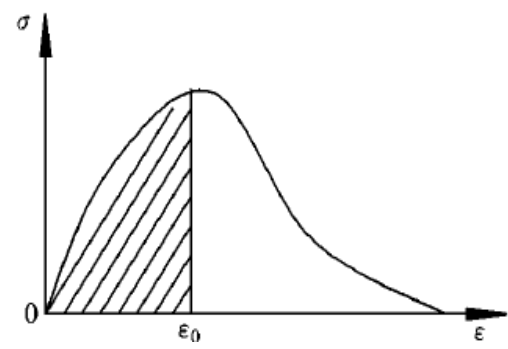

Fig 1 Low temperature be nding test curve

\section{$\mathbf{J}$ integral}

In elastic-plastic fracture mechanics, in order to consider the effect of the crack tip plasticity deformation, Rice, applying the theory to avoid solving the stress field of crack front mathematical difficulties, put forward the $\mathbf{J}$ integral principles. The principle thinks when $\mathrm{J}$ integral reaches the critical value $\mathrm{JC}$, fracture become instable. So, the critical $\mathrm{J}$ integral value $\mathrm{J}_{\mathrm{C}}$ is regard as indicators of the fracture toughness of materials.

$$
J=\int_{\Gamma}\left(\omega d y-T_{i} \frac{\partial u_{i}}{\partial x} d s\right)
$$


When $\mathbf{J}$ integral around the crack tip reaches the critical value $\mathrm{J}_{\mathrm{C}}$, crack began to expand. The critical value called the fracture toughness is a material constant and it reflects the ability of the material resistance to crack propagation and reflects the ability of crack resistance of material in elastoplastic phase.

\section{Cohesion model CZM}

Compared with the linear elastic fracture mechanics and elastoplastic fracture mechanics, the cohesion model CZM is a kind of research method of crack failure, which has been used to analyze the formation and extension of cracks in asphalt mixture. The crack interface cohesion and the relative displacement used to definite the model of cohesion. The cohesion force and displacement relationship can be described by cohesion-displacement curve and the curve is shown in fig 2.

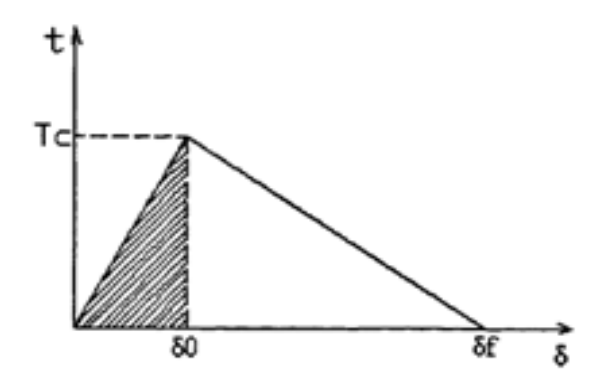

Fig 2 The curve of the bilinear $\mathrm{CZM}$

In fig $2, \delta_{f}$ - fracture plane maximum opening displacement, $T_{C}$ - tensile strength。

Using the fracture energy, tensile strength and opening displacement, coupled with curve, to evaluate the anti-cracking performance of asphalt mixture.

\section{Test method}

\section{$J$ integral}

Specimen size of $\mathbf{J}$ integral test is $40 \mathrm{~mm}$ x $250 \mathrm{~mm}$ x $40 \mathrm{~mm}$, span is $200 \mathrm{~mm} \mathrm{~L}$, incision depth is $21.5 \mathrm{~mm}$, the test temperature is $10^{\circ} \mathrm{C}, 5^{\circ} \mathrm{C}$ and $0{ }^{\circ} \mathrm{C},-5^{\circ} \mathrm{C},-10^{\circ} \mathrm{C}$, and the loading rate is 1 $\mathrm{mm} / \mathrm{min}$.

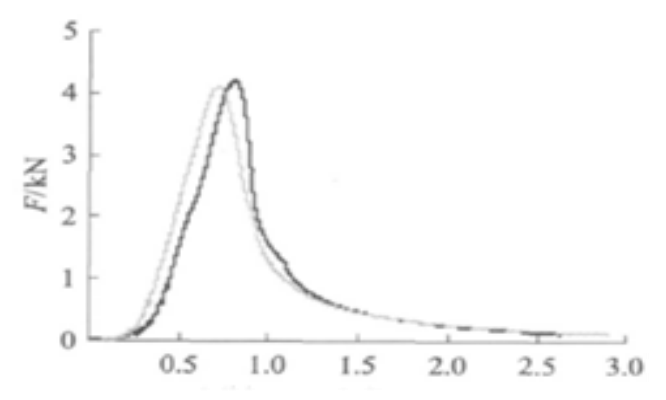

Fig 3 Load- deflection curve

Fracture can be calculated by the equation (3)

$$
G_{c}=\frac{U}{b\left(h_{0}-a\right)}
$$

Equation:

$\mathrm{U}$ is the area at the bottom of the deflection curve (fig 3), $\mathrm{J} ; \mathrm{b}$ is width of the beam, m; $h_{0}$ is height of the beam, m; a is kerf depth, m. Fracture toughness can be calculated by the equation (4) 


$$
J_{c}=\frac{\eta\left(U_{T}-U_{e}^{n c}\right)}{b\left(h_{0}-a\right)}
$$

Equation:

$\eta$ is a constant related to the size of the kerf width; $U_{T}$ is the area below the maximum load, $\mathrm{J} ; U_{e}^{n c}$ is elastic energy stored in ductile zone, $\mathrm{J}$; When the cross ratio $\mathrm{L} / \mathrm{h} 0$ of the specimen is equal to $4, U_{e}^{n c}$ can be ignored. This paper uses crack beam $\left(a / h_{0}=0.17\right)$, when evaluate the anti-crack performance, the value of $\eta$ will not affect the result, so $\eta$ will be assignment to 2.The bigger the critical fracture toughness is, the better crack resistance of asphalt mixture is 。

\section{Cohesion model test}

The parameters of fracture and cracking strength can be determined through the test. The opening displacement can be calculated using the formula of (5). The curve of the bilinear CZM was draw using the above parameters and assume that $\delta_{0}=0.15 \delta_{f}$ 。

$$
G_{C}=\frac{1}{2} T_{C}
$$

Among them, $G_{C}$ - fracture energy, $\delta_{f}$ - opening displacement, $T_{C}$ - strength of extension。

\section{Raw materials technical nature}

Asphalt is SBS modified asphalt. The aggregate is the different particle size of limestone rubble. The nature of mineral powder made from limestone grinding without aggregation is good. Mixture gradations are AC-13, SMA-13 and CAM. Mineral aggregate of three kinds of mixture gradation was optimal design. The results are shown in table 1.

The Marshall method is adopted as a mixture of specimen molding method. The optimum asphalt content of asphalt mixture by Marshall is obtained. Different types of Marshall specimen were tested, the results are shown in table 2.

Table 1 Mineral aggregate gradation design

\begin{tabular}{cccccccccccc}
\hline \multirow{2}{*}{$\begin{array}{c}\text { sieve-pore } \\
\text { size }\end{array}$} & 16.0 & 13.2 & 9.5 & 4.75 & 2.36 & 1.18 & 0.60 & 0.30 & 0.15 & 0.075 \\
\cline { 2 - 10 } & 100.0 & 91.1 & 75.2 & 46.8 & 36.7 & 23.1 & 17.7 & 10.5 & 7.0 & 6.0 \\
AC-13 & 100.0 & 90.0 & 70.5 & 33.1 & 23.9 & 19.2 & 17.3 & 14.9 & 13.5 & 12.5 \\
SM A-13 & 100.0 & 95.0 & 87.0 & 74.0 & 57.0 & 0.0 & 26.0 & 14.0 & 6.0 & 5.0 \\
CAM & 10.0 &
\end{tabular}

\begin{tabular}{|c|c|c|c|}
\hline mixture type & $\begin{array}{c}\text { Asphalt } \\
\text { content } \\
/ \%\end{array}$ & $\begin{array}{c}\text { Bulk } \\
\text { density } \\
/ \text { g. } \mathrm{cm}^{-3}\end{array}$ & $\begin{array}{c}\text { Void } \\
\text { fraction } \\
\qquad / \%\end{array}$ \\
\hline $\mathrm{AC}-13$ & 4.9 & 2. 466 & 3.4 \\
\hline SMA-13 & 5.4 & 2.510 & 3.4 \\
\hline CAM & 5.8 & 2.417 & 3.6 \\
\hline
\end{tabular}

Table 2 Different structure types of mix ture volume parameter test results 


\section{Analysis of test result}

\section{Test results and analysis of the critical strain energy}

The test carried on according to the methods and steps of low-temperature bending test. The test temperature is $10^{\circ} \mathrm{C} 、 5^{\circ} \mathrm{C} 、 0^{\circ} \mathrm{C} 、-5^{\circ} \mathrm{C} 、-10^{\circ} \mathrm{C}$. The curve of load and deformation was converted to stress -strain curve. Regression equation was given out and it is parabola. Origin8.0 software can be used to calculate the peak strain values and the integral is used to calculate the critical strain energy density. Test results as shown in fig 4.

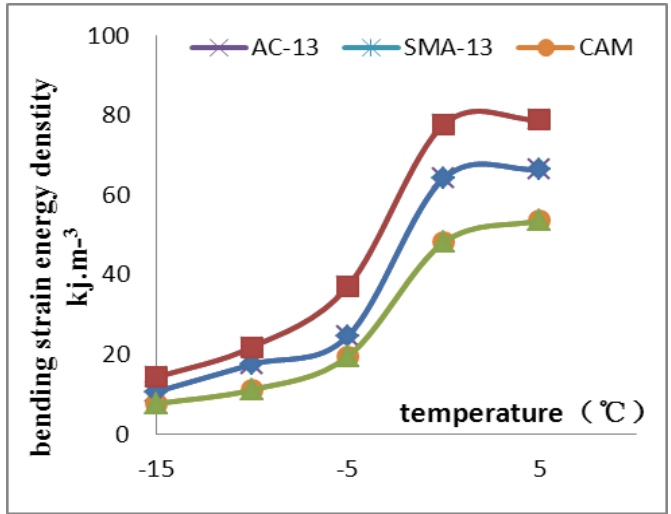

Fig 4 The bending strain energy density under different temperature

Can be seen from the fig 4 , under $0{ }^{\circ} \mathrm{C}$, with the increasing of temperature, the bending strain energy is gradual increasing. So, asphalt mixture in the higher the temperature is not easy to break. On the other hand, the lower the temperature, the asphalt mixture is prone to fracture. Above $0^{\circ} \mathrm{C}$, the changes of the bending strain energy of asphalt mixture is not big and the main reason under low temperature condition, is that the asphalt mixture mainly shows linear elastic material, but with the increasing of test temperature, plastic characteristics of asphalt mixture gradually strengthened. Therefore, when we evaluate the low temperature crack resistance of asphalt mixture, the test temperature of low-temperature bending test is controlled under $0{ }^{\circ} \mathrm{C}$, because, under this condition, asphalt mixture mainly shows elastic properties.

\section{Analysis of $\mathbf{J}$ integral test results}

Sample prepared by three kinds of asphalt mixture of AC-13, SMA-13 and CAM under the condition of optimum asphalt content and test temperature is $10^{\circ} \mathrm{C}, 5^{\circ} \mathrm{C}$ and $0^{\circ} \mathrm{C}, 5^{\circ} \mathrm{C}, 10^{\circ} \mathrm{C}$. The experimental device adopts microcomputer control electronic universal testing machine. The paper uses origin8.0 to determine peak and area of the test curve and uses the formula (3) and formula (4) to calculate the fracture energy and fracture toughness.

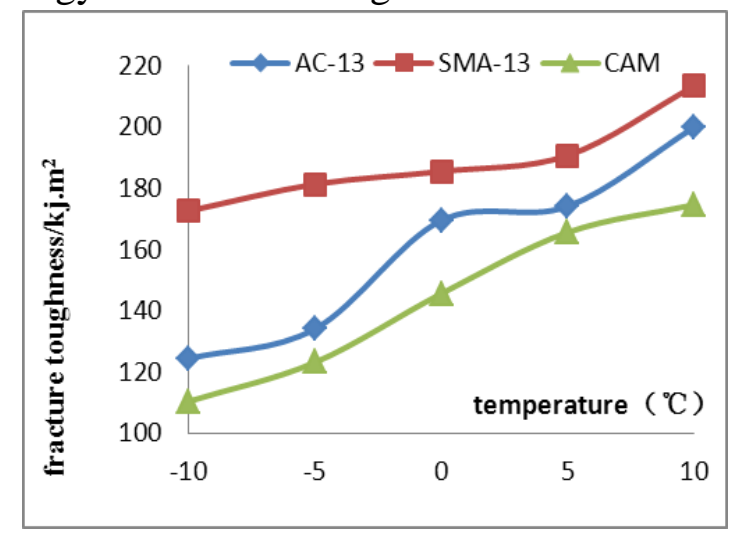

Fig 5 The fracture toughness under different temperatures

Can be seen from the fig 5, the anti-cracking performance of SMA is better than the other two 
kinds of asphalt mixture. We can use structure theory to explain the differences. SMA is the skeleton dense structure, because mineral aggregate skeleton structure plays a leading role and provides the embedded crowded ability. While AC and CAM are suspended dense structure and cracking strength is formed by the compositions such as asphalt, fine aggregate. When the temperature is low, the performance of the asphalt material shows the brittle characteristics and easy to fracture. Therefore, the skeleton dense structure has obvious advantages in terms of crack resistance.

\section{Analysis of test results}

The value of fracture and the tensile strength got according to the test. Opening displacement can be calculated by type (5). Draw diagrams using the experimental data and the test result are shown in fig6.

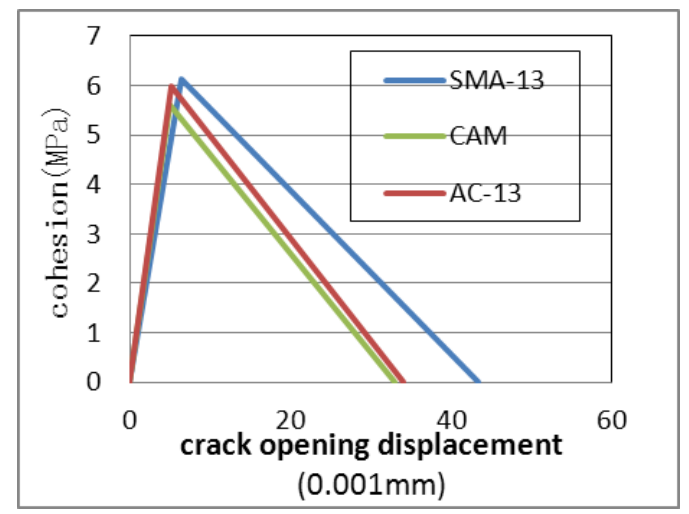

Fig 6 Relationship of cohesion and opening displacement

From the fig 6, we can see:

(1) Fracture energy, tensile strength and crack formed opening displacement value of SMA-13 is greater than $\mathrm{AC}-13$ and $\mathrm{CAM}$;

(2) Compared the SMA-13 with AC-13 type asphalt mixture. The fracture energy of SMA-13 of is 1.31 times than the fracture energy of the AC-13. Crack opening displacement of SMA - 13 is 1.27 times than the crack opening displacement of AC-13;

(3) fracture energy of AC-13 is 1.10 times than of CAM. The crack opening displacement of $\mathrm{AC}-13$ is 1.03 times that of the AC-13.

\section{conclusions}

1、 When the temperature is lower than $0^{\circ} \mathrm{C}$, using the bending strain energy density threshold to evaluate the low temperature crack resistance of asphalt mixture is reasonable

2、 Test results show that the anti-cracking performance of the SMA-13 is optimal compared with other two mixtures based on the $\mathrm{J}$ integral, cohesion in the model.

3、 Test results show that the bending strain energy density threshold (under certain temperature conditions), fracture energy, fracture toughness and crack opening displacement model based on cohesion index can evaluate the crack resistance of asphalt mixture.

\section{References}

[1] Liu Tao, Hao Peiwen. Research on appraisal method of low temperature crack resistance for asphalt mixture $[\mathrm{J}]$. Journal of tongji university (natural science edition), 2002, 30 (12): 1468-1471. 
[2] Li Feng, Zeng Wei, Shi Xiaopei. Evaluation on the crack resistance and influence factors at low temperature of asphalt mixture $[\mathrm{J}]$. Journal of Shandong construction university, 2012, 27 (6): 555-559.

[3] Xu Haojun. Study on Drought alpine region Asphalt mixture Crack resistance at low temperature. Master's degree thesis. Chang'an university.2008.

[4] Zhang Hong. Evaluation methods of asphalt-mixture's anti-cracking performance at low temperature $[\mathrm{J}]$.Journal of Chang'an University: Natural Science, 2002, 22( 4) :5-8.

[5] Wang Gang,Wang Binggang,Ma Biao.Comprehensive evolution method for anti-cracking performance of ATB [J] .Highway,2008(4):55-59.

[6] GeZhesheng, Huang XiaomingXu-Guoguang. Evaluation of-asphalt- mixture's- low-temperature-anti-cracking-performance by curvature strain energy method [J]. Journal of Southeast University:NaturaScience,2002,32(4):653-655.

[7] Hao Peiwen,Zhang Dengliang,Hu Xining. Evaluation- method for low temperature anti-cracking performance of asphalt mixture $[\mathrm{J}]$.Journal of Xi'an Highway University,2000,20(3):1-4.

[8] Liu Jinghui, Wang Duan-yi, Liu Yu. Evaluation of the fracture resistance of asphalt mixture using the J-integral.

[9] Dongre R, M G Sharma, DA Anderson. Development of fracture criterion for asphalt mixes at low temperatures [J]. In Transportation Research Record :Journal of the Transportation Research Board ,No.1228 , TRB, National Research Council , Washing ton, D.C, 1989 :94-105.

[10] Zhang Dong, Huang Xiaoming, Zhao Yongli.Comparative

Study-on-the-Evaluation-method-of-the-Fracture-Resistance of Asphalt Mixtures [ J J Journal of building materials. 2012,15(2):222-226.

[11] Zhang Dong. Research on fracture of asphalt pavements based on cohesive zone mode [D]. Nanjing:School of Transportation,Southeast University,2010.

[12] Zhao Yongli, Zhang Dong. Study of Low Temperature Cracking of Asphalt Pavement Based on Cohesive Zone Model [J]. Journal of Highway and Transportation Research and Development, 2010, 27 (1): 11-15. 